\title{
Myopia prevalence and risk factors in children
}

This article was published in the following Dove Press journal:

Clinical Ophthalmology

\author{
Christos Theophanous \\ Bobeck S Modjtahedi ${ }^{2,3}$ \\ Michael Batech ${ }^{4}$ \\ David S Marlin' \\ Tiffany Q Luong ${ }^{4}$ \\ Donald S Fong ${ }^{2-4}$ \\ 'Department of Ophthalmology, \\ Southern California Medical Group, \\ Los Angeles, CA, USA; ${ }^{2}$ Department of \\ Ophthalmology, Southern California \\ Permanente Medical Group, Baldwin \\ Park, CA, USA; ${ }^{3}$ Eye Monitoring \\ Center, Kaiser Permanente Southern \\ California, Baldwin Park, CA, USA; \\ ${ }^{4}$ Department of Research and \\ Evaluation, Southern California \\ Permanente Medical Group, Pasadena, \\ CA, USA
}

Purpose: To evaluate the prevalence and risk factors for pediatric myopia in a contemporary American cohort.

Methods: A cross-sectional study of pediatric patients enrolled in the Kaiser Permanente Southern California health plan was done. Eligible patients were 5- to 19-years old between January 1, 2008, through December 31, 2013, and received an ophthalmologic or optometric refraction. Electronic medical records were reviewed for demographic data, refraction results, and exercise data. Prevalence and relative risks of myopia (defined as $\leq-1.0$ diopter) were characterized. Age, sex, race/ethnicity, median neighborhood income, and minutes of exercise per day were examined as risk factors.

Results: There were 60,789 patients who met the inclusion criteria, of which $41.9 \%$ had myopia. Myopia was more common in older children (14.8\% in 5- to 7 -year olds, $59.0 \%$ in 17 - to 19-year olds). Asian/Pacific Islander patients (OR 1.64, CI 1.58-1.70) had an increased rate of myopia compared to White patients as did African Americans to a lesser extent (OR 1.08, CI 1.03-1.13). Median neighborhood household income of \$25,000-40,000 was associated with lower rates of myopia (OR 0.90, CI 0.83-0.97) compared to median neighborhood household incomes less than $\$ 25,000$. Having at least $60 \mathrm{~min}$ of daily exercise was associated with lower prevalence of myopia (OR 0.87, CI 0.85-0.89).

Discussion: Myopia was common in this large and diverse Southern Californian pediatric cohort. The prevalence of myopia increases with age. Asian children are at highest risk for myopia. Exercise is associated with a lower rate of myopia and represents an important potentially modifiable risk factor that may be a target for future public health efforts.

Keywords: children, epidemiology, exercise, refractive error, myopia, pediatrics, prevalence, public health

\section{Introduction}

Myopia is the most common ophthalmic condition in the world with an estimated $22.9 \%$ of the world population, or 1.406 billion people, being affected. ${ }^{1,2}$ An additional $2.7 \%$ of people, 163 million, are estimated to have high myopia..$^{2-4}$ The estimated economic impact of uncorrected refractive error is estimated to be a loss of $\$ 202$ billion of global gross domestic product. ${ }^{5}$ Costs of spectacle correction tend to burden low-income patients disproportionately. ${ }^{6}$ If untreated, myopia can inhibit academic performance in children. ${ }^{7}$ A recent estimate suggests that visual impairment among preschool children will increase by $26 \%$ by 2060 with uncorrected refractive error comprising $69 \%$ of cases. ${ }^{8}$ Myopes carry higher risks of important causes of ocular morbidity including retinal detachment, glaucoma, myopic macular degeneration, and cataracts. ${ }^{9}$ Uncorrectable visual impairment is seen in $4 \%$ and $39 \%$ of 75 year olds with myopia and high myopia, respectively. ${ }^{10}$ The disease burden of myopia is expected to increase, with $49.8 \%$ of individuals ( 4.758 billion people) being myopic and $9.8 \%$ of the population (938 million people) being highly myopic by $2050 .{ }^{2}$ Correspondingly,
Correspondence: Bobeck S Modjtahedi Eye Monitoring Center, Kaiser Permanente Southern California, I0 I I Baldwin Park Blvd, Baldwin Park, CA 91706, USA

Email BobModj@gmail.com 
uncorrectable visual impairment is estimated to increase 7-fold to 13-fold by 2055 in high-risk areas. ${ }^{10}$

Many East Asian countries are particularly affected, where the prevalence of myopia in schoolchildren exceeds $90 \%$ in some regions. ${ }^{11-13}$ Although genetic factors play a role in the development of myopia, the rapid growth in prevalence is likely attributable to environmental and lifestyle factors. ${ }^{2}$ Prior studies have demonstrated an association between myopia and near-work activities such as studying, reading, and screen time among children. ${ }^{14}$ Animal experiments suggest that near work may result in hyperopic defocus of the retina leading to excessive growth of the eye with resultant myopia. ${ }^{15}$ Additionally, time spent outdoors has been shown to be protective against myopia, ${ }^{16}$ potentially due to light stimulation of retinal dopamine which discourages axial growth. ${ }^{17}$

Public health interventions are needed to help stem the growing myopia epidemic. Pharmacologic interventions, namely atropine, have been employed with some success to slow the progression of myopia. ${ }^{18-21}$ Prior studies have demonstrated an inverse relationship between myopia rates and physical activity ${ }^{22}$ and sports participation ${ }^{16,23,24}$ where myopia was defined as $\leq-0.5$ diopters (D), ${ }^{23,24} \leq-0.75 \mathrm{D},{ }^{16}$ or $\leq-1$ D. ${ }^{22}$ Public health initiatives may include pharmacologic interventions and promotion of outdoor time in children.

Although the prevalence of myopia has been extensively examined in East Asian populations, fewer large-scale studies have been done on American children. Additionally, largescale studies examining the influence of lifestyle factors on myopia rates and progression in American children remain limited. This study evaluates the prevalence and risk factors for myopia among pediatric patients in a large, diverse, and real-world population in southern California.

\section{Methods}

This retrospective, cross-sectional study of Kaiser Permanente Southern California (KPSC) members was approved by the KPSC Institutional Review Board (IRB) and adhered to the tenets of the Declaration of Helsinki. The KPSC IRB did not require patient consent to be acquired for this retrospective chart review as no personally identifying patient information or images were to be published. This study was conducted in accordance with the Health Insurance Portability and Accountability Act.

\section{Study population}

Patients who were enrolled members of KPSC between January 1, 2008, through December 31, 2013, and received an ophthalmologic or optometric refraction between the ages of 5 and 19 years old were included in this study. KPCS patients are broadly representative of the ethnic and socioeconomic diversity of southern California. Patients without a recorded refraction during this period were excluded.

\section{Measurement of refractive error}

Refractive error measurements were collected from KPSC electronic health records and used to calculate each refraction's spherical equivalent. Patients could have multiple refractions recorded in their electronic chart for any given visit including autorefraction, cycloplegic refraction, and/or subjective refractions. The different refractions are not coded electronically in a way that can be differentiated upon en masse data extraction for a study. The last refractive measurement for any given visit was used for analysis for this study - this refraction is what was used for dispensing corrective glasses (when clinically indicated) and was typically the finalized refraction after subjective refinement. Data were collected for the right and left eyes separately with the right eye measurements being used for analysis. Myopia was defined in this study as refractive error $\leq-1.0 \mathrm{D}$ and high myopia was defined as refractive error $\leq-6.0 \mathrm{D}$. This definition for myopia was used since lower levels of myopia are often left uncorrected and not deemed clinically significant by clinicians, and also because the frequent use of subjective refraction may overestimate the degree of myopia in children. Unless otherwise described, all variables examined in the study were those on the date of the refractive error measurement for which the patient was myopic or the latest refractive error ever measured in the study period. For the purposes of the cross-sectional study, this date was the index date.

\section{Data collection}

Demographic data were collected for each patient including sex, age at time of refraction, race (White, African American, Asian/Pacific Islander, Other/Multiple/Unknown), ethnicity (Hispanic vs non-Hispanic), and body mass index (BMI) percentile for age and sex defined by the Centers for Disease Control and Prevention. ${ }^{25}$ Median neighborhood household income was estimated based on zip code using conversion tables from the University of Michigan Population Studies Center. ${ }^{26}$ Responses to clinic intake questions asking the frequency per week and per session of exercise were also collected. We used the responses from these two questions to determine the minutes of exercise per day and classified patients as having exercised less than or at least 60 min per day. 


\section{Data analysis}

We tested for association or differences in all demographic or social characteristics at the index date between patients classified with myopia or not using chi-square or Fisher's exact test for categorical variables and $t$-test or Wilcoxon's ranked-sum test for continuous variables, as appropriate. Normality for parametric testing was determined using Shapiro-Wilk's test of normality. Statistical significance was considered at the 5\% type-I error rate and all tests of association or difference were 2-sided. We used robust Poisson regression to examine ORs and $95 \% \mathrm{CI}$ limits for myopia in both crude models that included only the variable being examined or all variables together in the same model for the multivariable analysis. CI that included 1.0 were considered not statistically significant for these results. All analyses were conducted using SAS/STAT Version 12.0 (SAS Institute Inc., Cary, NC, USA).

\section{Results}

A total of 708,369 pediatric KPSC members were assessed for the study. Of those, 60,789 met the inclusion criteria, as shown in Figure 1. Of these patients, $53.9 \%$ of patients were female, while $56.3 \%$ of patients were Hispanic, 37.7\% were White, $12.5 \%$ were Asian/Pacific Islander, and 10.0\% were African American. At least 60 min of daily exercise was reported by $38.2 \%$ of patients. Table 1 summarizes the demographics of the cohort.

Overall, $41.9 \%$ of patients had myopia and $2.7 \%$ of patients had high myopia. The prevalence of myopia increased with age from $14.7 \%$ in 5 - to 7 -year olds to $59.0 \%$ in 17- to 19-year olds. High myopia also increased with age from $0.6 \%$ in 5 - to 7 -year olds to $4.9 \%$ of 17 - to 19 -year

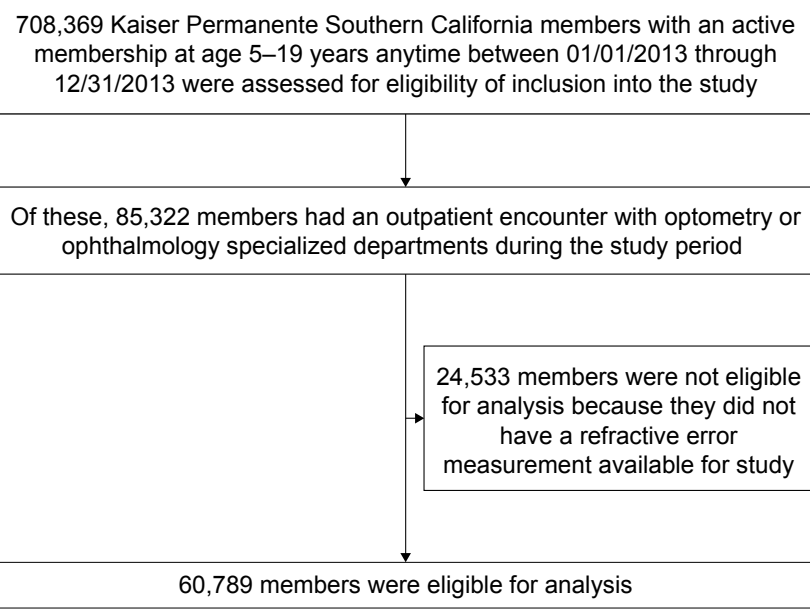

Figure I Study population selection. olds. Table 2 summarizes the myopia prevalence by age. Table 3 summarizes the degree of astigmatism found in each age group.

Crude and multivariable adjusted OR results are shown in Table 4. Asians/Pacific Islander (OR 1.64, CI 1.58-1.70) and to a lesser extent African American (OR 1.08, CI 1.03-1.13) race were significantly associated with myopia compared to White race. Hispanic ethnicity showed significant association with myopia in the crude model compared to non-Hispanics (OR 0.91, CI 0.90-0.93); however, the association was not significant on multivariate analysis (OR 0.99, CI 0.96-1.03). At least $60 \mathrm{~min}$ of daily exercise was significantly associated with lower myopia prevalence (OR 0.87, CI 0.85-0.89) as was median neighborhood household income of $\$ 25,000-40,000$ (OR 0.90, CI 0.83-0.97).

\section{Discussion}

Variation in myopia prevalence by geographic location has been well documented in the literature. ${ }^{18,27}$ East Asian countries demonstrate the highest pediatric prevalence rates. By age 18 , prevalence reaches $70 \%-90 \%$ in countries such as Hong Kong, China, Singapore, and Taiwan. ${ }^{3}$ In the present study, nearly $60 \%$ of children in this age group were myopic. In contrast, only $0.8 \%$ of Laotian children were myopic in one study ${ }^{28}$ and rates of refractive error can vary depending on if children live in rural or urban environments. ${ }^{29}$ Prevalence is low in Africa, with rates of myopia below $10 \%$ at age $15 .^{3,30}$ European and Australian children have lower myopia rates compared to our findings: $12 \%$ of Australian 11- to 15-year olds, ${ }^{31} 18 \%$ of Irish 12 - to 13 -year olds, ${ }^{24}$ and $29 \%$ of British 12- to 13 -year olds ${ }^{32}$ were found to be myopic. Comparatively, half of children of similar age were myopic in our study.

Myopia prevalence among American children has been less thoroughly studied with limited contemporary data available to understand trends in the United States within the context of the global surge of myopia. The Multi-Ethnic Pediatric Eye Disease Study characterized early childhood myopia and found that prevalence ranged from $~ 1 \%$ to $4 \%$ of White and Asian preschool children, respectively. ${ }^{33}$ The Collaborative Longitudinal Evaluation of Ethnicity and Refractive Error study, which measured refractive error for children age 5-17 between 1997 and 1998, found an overall prevalence of $9.2 \%{ }^{34}$ Another report from 1997 estimated that $\sim 20 \%$ of 12 -year olds were myopic ${ }^{35}$ compared to $49.4 \%$ of 11- to 13-year olds in our study. In comparison, our study found an overall prevalence rate of $41.9 \%$ in patients 5 - to 19 -year old and $49.4 \%$ among children 11 - to 13 -year old. To our knowledge, no other recent, large-scale study has stratified 
Table I Study population demographics

\begin{tabular}{|c|c|c|c|c|}
\hline Variables, N (\%) & $\begin{array}{l}\text { No myopia } \\
35,326 \text { (58.1\%) }\end{array}$ & $\begin{array}{l}\text { Myopia } \\
25,463 \text { (41.9\%) }\end{array}$ & $\begin{array}{l}\text { Total } \\
60,789(100.0 \%)\end{array}$ & $P$-value \\
\hline Age at eye examination & & & & $<0.001$ \\
\hline 5 to $<8$ years & $8,929(25.3 \%)$ & I,548 (6. I\%) & 10,477 (I7.2\%) & \\
\hline 8 to $<$ II years & $9,610(27.2 \%)$ & $4,66 \mid(18.3 \%)$ & $|4,27|$ (23.5\%) & \\
\hline II to $<$ I 4 years & $8,132(23 \%)$ & $7,94 \mathrm{I}(3 \mathrm{I} .2 \%)$ & $16,073(26.4 \%)$ & \\
\hline 14 to $<17$ years & 7,486 (21.2\%) & $9,633(37.8 \%)$ & $17,119(28.2 \%)$ & \\
\hline 17 to $<20$ years & $1,169(3.3 \%)$ & $1,680(6.6 \%)$ & $2,849(4.7 \%)$ & \\
\hline Sex & & & & 0.718 \\
\hline Female & $19,032(53.9 \%)$ & $13,756(54 \%)$ & 32,788 (53.9\%) & \\
\hline Male & I6,294 (46.1\%) & II,707 (46\%) & 28,001 (46.1\%) & \\
\hline Race & & & & $<0.001$ \\
\hline White & $\mid 4,567(4 \mid .2 \%)$ & $8,337(32.7 \%)$ & $22,904(37.7 \%)$ & \\
\hline African American & 3,740 (10.6\%) & $2,362(9.3 \%)$ & $6,102(10.0 \%)$ & \\
\hline Asian/Pacific Islander & $3,000(8.5 \%)$ & $4,570(17.9)$ & 7,570 (I2.5\%) & \\
\hline Other/Multiple/Unknown & $14,019(39.7 \%)$ & $10,194(40.0 \%)$ & $24,213(39.8 \%)$ & \\
\hline Ethnicity & & & & $<0.001$ \\
\hline Not Hispanic & $14,873(42.1 \%)$ & II,695 (45.9\%) & $26,568(43.7 \%)$ & \\
\hline Hispanic & $20,453(57.9 \%)$ & $13,768(54.1 \%)$ & $34,221(56.3)$ & \\
\hline Neighborhood household income (USD) & & & & $<0.001$ \\
\hline Less than $\$ 25,000$ & $710(2.5 \%)$ & $568(2.7 \%)$ & $\mathrm{I}, 278(2.6 \%)$ & \\
\hline$\$ 25,000-49,999$ & 9,328 (33.4\%) & 6,445 (3I.1\%) & I5,773 (32.4\%) & \\
\hline$\$ 50,000-99,999$ & $14,896(53.3 \%)$ & II,00I (53.I\%) & $25,897(53.2 \%)$ & \\
\hline$\$ 100,000$ or higher & $3,018(10.8 \%)$ & 2,705 (I3.1\%) & $5,723(11.8 \%)$ & \\
\hline Body mass index percentile for age and sex ${ }^{a}$ & & & & 0.763 \\
\hline Normal or under weight ( $<85$ th) & $20,367(60.4 \%)$ & $14,238(60.1 \%)$ & $34,605(60.3 \%)$ & \\
\hline Overweight (85th to $<95$ th) & $6,112(18.1 \%)$ & $4,340(18.3 \%)$ & $10,452(18.2 \%)$ & \\
\hline Moderately obese (95th-1.2×95th) & $6,634(19.7 \%)$ & $4,394(18.5 \%)$ & II,028 (19.2\%) & \\
\hline Extremely obese $(\geq 1.2 \times 95$ th $)$ & $630(1.9 \%)$ & $718(3.1 \%)$ & $\mathrm{I}, 348(2.3 \%)$ & \\
\hline Exercise per day & & & & $<0.001$ \\
\hline Less than $60 \mathrm{~min}$ & $14,685(59.6 \%)$ & $\mathrm{II}, \mathrm{II} 4$ (65.0\%) & $25,799(61.8 \%)$ & \\
\hline At least $60 \mathrm{~min}$ & $9,957(40.4 \%)$ & $5,986(35.0 \%)$ & I5,943 (38.2\%) & \\
\hline
\end{tabular}

Note: aBased on the sex-specific body mass index-for-age growth charts developed by the Centers for Disease Control and Prevention. ${ }^{25}$

myopia prevalence among American children from school age through adolescence. When viewed within the larger context of the available prevalence literature, the presented data support the notion that myopia is increasing in the United States and provides an important view into this epidemic.
Consistent with prior studies, Asian children remain at highest risk for myopia. ${ }^{33,35}$ African American children were also at slightly higher risk compared to White children, which is especially noteworthy as the rates of myopia in Africa tend to be low. ${ }^{3,30}$ Interestingly, Hispanic patients in our population

Table 2 Refractive error by age group

\begin{tabular}{|c|c|c|c|c|c|c|}
\hline $\mathbf{N}(\%)$ & 5-7 years & $8-10$ years & $11-13$ years & 14-16 years & $17-19$ years & Total \\
\hline$\geq 0.0 \mathrm{D}$ & 5,475 (52.3\%) & $5,185(36.3 \%)$ & $3,740(23.3 \%)$ & $2,866(16.7 \%)$ & $4 \mathrm{II}(\mathrm{I} .4 \%)$ & I7,677 (29.1\%) \\
\hline-0.0 to $>-1.0 \mathrm{D}$ & $3,454(33.0 \%)$ & 4,425 (31.0\%) & $4,392(27.3 \%)$ & $4,620(27.0 \%)$ & $758(26.6 \%)$ & 17,649 (29.0\%) \\
\hline-1.0 to $>-2.0 \mathrm{D}$ & 857 (8.2\%) & $2,013(14.1 \%)$ & $2,67 \mid(16.6 \%)$ & 2,985 (17.4\%) & 524 (I8.4\%) & 9,050 (14.9\%) \\
\hline-2.0 to $>-3.0 \mathrm{D}$ & $38 \mathrm{I}(3.6 \%)$ & I,300 (9.1\%) & $2,|3|(\mid 3.3 \%)$ & 2,446 (I4.3\%) & 425 (I4.9\%) & 6,683 (II.0\%) \\
\hline-3.0 to $>-4.0 \mathrm{D}$ & 139 (1.3\%) & 635 (4.4\%) & I,386 (8.6\%) & I,666 (9.7\%) & $293(10.3 \%)$ & $4, I 19$ (6.8\%) \\
\hline-4.0 to $>-5.0 \mathrm{D}$ & $68(0.6 \%)$ & 364 (2.6\%) & $824(5.1 \%)$ & I,07I (6.3\%) & 175 (6.1\%) & 2,502 (4.1\%) \\
\hline-5.0 to $>-6.0 \mathrm{D}$ & 40 (0.4\%) & 175 (1.2\%) & 473 (2.9\%) & 645 (3.8\%) & $122(4.3 \%)$ & I,455 (2.4\%) \\
\hline$\leq-6.0 \mathrm{D}$ & $63(0.6 \%)$ & 174 (I.2\%) & $456(2.8 \%)$ & $820(4.8 \%)$ & I4I (4.9\%) & $\mathrm{I}, 654$ (2.7\%) \\
\hline Myopia $(\leq-I D)$ & I,548 (I4.7\%) & $4,66 \mathrm{I}(32.7 \%)$ & $7,94 I$ (49.4\%) & $9,633(56.3 \%)$ & $\mathrm{I}, 680$ (59.0\%) & 25,463 (4I.9\%) \\
\hline
\end{tabular}

Abbreviation: $\mathrm{D}$, diopter. 
Table 3 Mean and SD of astigmatism by age group

\begin{tabular}{lll}
\hline Age & Cylinder & \\
\cline { 2 - 3 } & Mean & SD \\
\hline 5 to $<8$ years & 1.01 & 1.05 \\
8 to $<$ II years & 0.83 & 0.97 \\
II to $<14$ years & 0.82 & 0.93 \\
14 to $<17$ years & 0.86 & 0.94 \\
17 to $<20$ years & 0.85 & 0.94 \\
\hline
\end{tabular}

showed no significant difference in myopia risk compared to non-Hispanics, which contrasts with previous studies. ${ }^{32,34}$ These ethnic differences warrant further examination, as rates of eye care service usage differ significantly by ethnic populations, with Hispanic and African American children at highest risk for poor access to care..$^{36,37}$

Given the profound impact myopia has on an individual and population basis, interventions are needed to help mitigate the prevalence and severity of this condition. This study demonstrates that exercise may be a modifiable risk factor that could represent a future target for public health interventions. Patients with self-reported exercise of at least $1 \mathrm{~h}$ per day had a $10 \%$ lower prevalence of myopia. This finding is consistent with prior studies that have identified a protective effect of time outdoors ${ }^{38}$ and sports participation. ${ }^{16,23,24}$ This effect may be due in large part to increased retinal dopamine release cause by sunlight exposure, which reduces eye elongation..$^{39,40}$ Notably, the relationship between myopia

Table 4 Crude and multivariable adjusted Poisson OR estimates for myopia

\begin{tabular}{|c|c|c|}
\hline Variables & $\begin{array}{l}\text { Crude OR } \\
(95 \% \mathrm{Cl})\end{array}$ & $\begin{array}{l}\text { Adjusted OR } \\
(95 \% \mathrm{Cl})\end{array}$ \\
\hline \multicolumn{3}{|l|}{ Patient sex } \\
\hline Male & Reference & Reference \\
\hline Female & $1.00(0.98-1.02)$ & $1.00(0.97-1.02)$ \\
\hline \multicolumn{3}{|l|}{ Race } \\
\hline White & Reference & Reference \\
\hline African American & $1.06(1.03-1.10)$ & $1.08(1.03-1.13)$ \\
\hline Asian/Pacific Islander & $1.66(1.62-1.70)$ & $1.64(1.58-1.70)$ \\
\hline Other/Multiple/Unknown & $1.16(1.13-1.18)$ & $1.18(1.14-1.22)$ \\
\hline \multicolumn{3}{|l|}{ Ethnicity } \\
\hline Not Hispanic & Reference & Reference \\
\hline Hispanic & $0.91(0.90-0.93)$ & $0.99(0.96-1.03)$ \\
\hline \multicolumn{3}{|c|}{ Neighborhood household income (in USD) } \\
\hline Less than $\$ 25,000$ & Reference & Reference \\
\hline$\$ 25,000-49,999$ & $0.92(0.86-0.98)$ & $0.90(0.83-0.97)$ \\
\hline$\$ 50,000-99,999$ & $0.96(0.90-1.02)$ & $0.93(0.86-1.01)$ \\
\hline$\$ 100,000$ or higher & $1.06(0.99-1.14)$ & $1.03(0.94-1.12)$ \\
\hline \multicolumn{3}{|l|}{ Exercise per day } \\
\hline Less than $60 \mathrm{~min}$ & Reference & Reference \\
\hline At least $60 \mathrm{~min}$ & $0.87(0.85-0.89)$ & $0.87(0.85-0.89)$ \\
\hline
\end{tabular}

Note: Bold data represent statistically significant associations. rates and exercise was independent of BMI. Exercise is a cornerstone to healthy lifestyle practices and is already being encouraged through multiple widespread public health campaigns in children. The health benefits of exercise are numerous and lowering the risk of myopia may be another benefit of exercise that ophthalmologists can discuss with their patients and their parents. Due to the retrospective nature of this study, a causative relationship cannot be established. The observed relationship between exercise and myopia may be because exercise functions as a surrogate for other practices, such as outdoor time (which has been demonstrated to reduce myopia risk), which serve as unaccounted for confounders.

Patients who lived in a neighborhood whose median family income was between $\$ 25,000$ and 49,000 had a lower rate of myopia compared to those in neighborhoods whose median family income was less than $\$ 25,000$. A trend was seen in increasing myopia for higher incomes, but did not achieve statistical significance in the other income brackets. A limitation of this study is that patients' family incomes were not known and instead the median income of their neighborhood was used. Although this provides a reflection of their surrounding socioeconomic environment, it lacks the granular detail of their own individual circumstances. It is foreseeable that both individual as well as community level socioeconomics play a role in determining myopia risk, and further study is necessary to discern the relative influence of each factor. Prior studies in China and Korea showed that higher family income was associated with higher risk of myopia. ${ }^{41,42}$ This trend likely relates to lifestyle differences such as amount of near work, reading, outdoor time, or computer time, but not differences in exercise as this was controlled for in our analysis.

The size and diversity of the population studied herein is a significant strength of this study and makes the findings more generalizable to the American patient experience. There are several limitations to this study. The cross-sectional design of this study does not allow for causal relationships to be established. Additionally, the assessment of daily exercise relies on report from patients or their parents, and as a binary question asked at intake, there is limited granularity in how many hours of exercise or what type of exercise is most associated with lower rates of myopia. Confounding is an inherent limitation to any retrospective study such as this. Further studies should explore the optimal type and timing of exercise to influence myopia progression. Prospective studies are needed to fully evaluate whether encouraging exercise in children can modify the risk of myopia. 


\section{Acknowledgment}

Financial support for this project was provided by the Kaiser Permanente Southern California Regional Research Committee.

\section{Disclosure}

Donald S Fong has received grants from Allergan, ThromboGenics, Regeneron, and Nightstar. The other authors report no conflicts of interest in this work.

\section{References}

1. Chua J, Wong TY. Myopia-the silent epidemic that should not be ignored. JAMA Ophthalmol. 2016;134(12):1363-1364.

2. Holden BA, Fricke TR, Wilson DA, et al. Global prevalence of myopia and high myopia and temporal trends from 2000 through 2050. Ophthalmology. 2016;123(5):1036-1042.

3. Rudnicka AR, Kapetanakis VV, Wathern AK, et al. Global variations and time trends in the prevalence of childhood myopia, a systematic review and quantitative meta-analysis: implications for aetiology and early prevention. Br J Ophthalmol. 2016;100(7):882-890.

4. Bourne RR, Stevens GA, White RA, et al. Causes of vision loss worldwide, 1990-2010: a systematic analysis. Lancet Glob Health. 2013; 1(6):e339-e349.

5. Fricke TR, Holden BA, Wilson DA, et al. Global cost of correcting vision impairment from uncorrected refractive error. Bull World Health Organ. 2012;90(10):728-738.

6. Resnikoff S, Pascolini D, Mariotti SP, Pokharel GP. Global magnitude of visual impairment caused by uncorrected refractive errors in 2004 . Bull World Health Organ. 2008;86(1):63-70.

7. Maples WC. Visual factors that significantly impact academic performance. Optometry. 2003;74(1):35-49.

8. Varma R, Tarczy-Hornoch K, Jiang X. Visual impairment in preschool children in the United States: demographic and geographic variations from 2015 to 2060. JAMA Ophthalmol. 2017;135(6):610-616.

9. Smith MJ, Walline JJ. Controlling myopia progression in children and adolescents. Adolesc Health Med Ther. 2015;6:133-140.

10. Tideman JW, Snabel MC, Tedja MS, et al. Association of axial length with risk of uncorrectable visual impairment for Europeans with myopia. JAMA Ophthalmol. 2016;134(12):1355-1363.

11. Lin LL, Shih YF, Hsiao CK, Chen CJ. Prevalence of myopia in Taiwanese school children: 1983 to 2000. Ann Acad Med Singapore. 2004;33(1):27-33

12. Saw SM. A synopsis of the prevalence rates and environmental risk factors for myopia. Clin Exp Optom. 2003;86(5):289-294.

13. Dolgin E. The myopia boom. Nature. 2015;519(7543):276-278.

14. Saw SM, Chua WH, Hong CY, et al. Nearwork in early-onset myopia. Invest Ophthalmol Vis Sci. 2002;43(2):332-339.

15. Mcbrien NA, Moghaddam HO, Reeder AP. Atropine reduces experimental myopia and eye enlargement via a nonaccommodative mechanism. Invest Ophthalmol Vis Sci. 1993;34(1):205-215.

16. Mutti DO, Mitchell GL, Moeschberger ML, Jones LA, Zadnik K. Parental myopia, near work, school achievement, and children's refractive error. Invest Ophthalmol Vis Sci. 2002;43(12):3633-3640.

17. Read SA, Collins MJ, Vincent SJ. Light exposure and physical activity in myopic and emmetropic children. Optom Vis Sci. 2014;91(3):1-341.

18. Morgan IG, Ohno-Matsui K, Saw SM, Myopia SSM. Myopia. Lancet. 2012;379(9827):1739-1748.

19. Huang J, Wen D, Wang Q, et al. Efficacy comparison of 16 interventions for myopia control in children: a network meta-analysis. Ophthalmology. 2016;123(4):697-708.

20. Gong Q, Janowski M, Luo M, et al. Efficacy and adverse effects of atropine in childhood myopia: a meta-analysis. JAMA Ophthalmol. 2017; 135(6):624-630
21. Pineles SL, Kraker RT, Vanderveen DK, et al. Atropine for the prevention of myopia progression in children: a report by the American Academy of Ophthalmology. Ophthalmology. 2017;124(12):1857-1866.

22. Guggenheim JA, Northstone K, Mcmahon G, et al. Time outdoors and physical activity as predictors of incident myopia in childhood: a prospective cohort study. Invest Ophthalmol Vis Sci. 2012;53(6):2856-2865.

23. Dirani M, Tong L, Gazzard G, et al. Outdoor activity and myopia in Singapore teenage children. Br J Ophthalmol. 2009;93(8):997-1000.

24. O'Donoghue L, Mcclelland JF, Logan NS, et al. Refractive error and visual impairment in school children in Northern Ireland. $\mathrm{Br} J$ Ophthalmol. 2010;94(9):1155-1159.

25. Centers for Disease Control and Prevention. Data Table of BMI-forage Charts; 2017. Available from: https://www.cdc.gov/growthcharts/ html_charts/bmiagerev.htm. Accessed November 6, 2017.

26. University of Michigan Population Studies Center. Zip Code Characteristics: Mean and Median Household Income; 2017. Available from: http://www.psc.isr.umich.edu/dis/census/Features/tract2zip/. Accessed November 6, 2017.

27. Pan CW, Ramamurthy D, Saw SM. Worldwide prevalence and risk factors for myopia. Ophthalmic Physiol Opt. 2012;32(1):3-16.

28. Casson RJ, Kahawita S, Kong A, et al. Exceptionally low prevalence of refractive error and visual impairment in schoolchildren from Lao People's Democratic Republic. Ophthalmology. 2012;119(10): 2021-2027.

29. Gao Z, Meng N, Muecke J, et al. Refractive error in school children in an urban and rural setting in Cambodia. Ophthalmic Epidemiol. 2012; 19(1):16-22.

30. Naidoo KS, Raghunandan A, Mashige KP, et al. Refractive error and visual impairment in African children in South Africa. Invest Ophthalmol Vis Sci. 2003;44(9):3764-3770.

31. Ip JM, Huynh SC, Robaei D, et al. Ethnic differences in refraction and ocular biometry in a population-based sample of 11-15-year-old Australian children. Eye. 2008;22(5):649-656.

32. Logan NS, Shah P, Rudnicka AR, Gilmartin B, Owen CG. Childhood ethnic differences in ametropia and ocular biometry: the Aston Eye Study. Ophthalmic Physiol Opt. 2011;31(5):550-558.

33. Wen G, Tarczy-Hornoch K, Mckean-Cowdin R, et al. Prevalence of myopia, hyperopia, and astigmatism in non-Hispanic white and Asian children: multi-ethnic pediatric eye disease study. Ophthalmology. 2013;120(10):2109-2116.

34. Kleinstein RN, Jones LA, Hullett S, et al. Refractive error and ethnicity in children. Arch Ophthalmol. 2003;121(8):1141-1147.

35. Zadnik K. The Glenn A. Fry award lecture (1995). Myopia development in childhood. Optom Vis Sci. 1997;74:603-608.

36. Heslin KC, Casey R, Shaheen MA, Cardenas F, Baker RS. Racial and ethnic differences in unmet need for vision care among children with special health care needs. Arch Ophthalmol. 2006;124(6):895-902.

37. Kemper AR, Bruckman D, Freed GL. Receipt of specialty eye care by children. Ambul Pediatr. 2003;3(5):270-274.

38. Rose KA, Morgan IG, Ip J, et al. Outdoor activity reduces the prevalence of myopia in children. Ophthalmology. 2008;115(8):1279-1285.

39. Ashby RS, Schaeffel F. The effect of bright light on lens compensation in chicks. Invest Ophthalmol Vis Sci. 2010;51(10):5247-5253.

40. Mccarthy CS, Megaw P, Devadas M, Morgan IG. Dopaminergic agents affect the ability of brief periods of normal vision to prevent formdeprivation myopia. Exp Eye Res. 2007;84(1):100-107.

41. Wu LJ, You QS, Duan JL, et al. Prevalence and associated factors of myopia in high-school students in Beijing. PLoS One. 2015;10(3): e0120764.

42. Lim HT, Yoon JS, Hwang SS, Lee SY. Prevalence and associated sociodemographic factors of myopia in Korean children: the 2005 third Korea National Health and Nutrition Examination Survey (KNHANES III). Jpn J Ophthalmol. 2012;56(1):76-81. 


\section{Publish your work in this journal}

Clinical Ophthalmology is an international, peer-reviewed journal covering all subspecialties within ophthalmology. Key topics include: Optometry; Visual science; Pharmacology and drug therapy in eye diseases; Basic Sciences; Primary and Secondary eye care; Patien Safety and Quality of Care Improvements. This journal is indexed on

Submit your manuscript here: http://www.dovepress.com/clinical-ophthalmology-journal
Dovepress

PubMed Central and CAS, and is the official journal of The Society of Clinical Ophthalmology (SCO). The manuscript management system is completely online and includes a very quick and fair peer-review system, which is all easy to use. Visit http://www.dovepress.com/ testimonials.php to read real quotes from published authors. 